\title{
O ensino remoto na percepção discente: desafios e benefícios
}

\author{
Remote teaching in student perception: challenges and benefits
}

Ana Carolina Oliveira Silva

Graduanda em Ciências Biológicas

Faculdade de Educação de Crateús/Universidade Estadual do Ceará - FAEC/UECE.

Crateús, Ceará - Brasil.

carolsilvaoliveira46@gmail.com

Shirliane de Araújo Sousa

Doutora em Ciência Animal.

Faculdade de Educação de Crateús/Universidade Estadual do Ceará - FAEC/UECE.

Crateús, Ceará - Brasil.

shirliane.araujo@uece.br

Jones Baroni Ferreira de Menezes Mestre em Ciências Fisiológicas.

Faculdade de Educação de Crateús/Universidade Estadual do Ceará - FAEC/UECE.

Crateús, Ceará - Brasil.

jones.baroni@uece.br

Resumo: A pandemia do novo corona vírus modificou a atuação de diversos setores em todo o mundo, entre eles a educação, obrigando pessoas e instituições a remodelarem suas atividades, cumprindo o distanciamento social, como prevenção à disseminação do vírus. No setor educacional, foi implantado o ensino remoto emergencial, como possibilidade de continuação das atividades escolares. Nesse cenário, a pesquisa pretende compreender, na visão de discentes brasileiros, quais os méritos e deméritos do Ensino Remoto Emergencial (ERE) para o contexto educacional. A pesquisa é caracterizada como um estudo de caso qualitativo, que teve a participação de 144 discentes mediante questionário on-line, no qual foi notado insatisfação, relacionados não só ao acesso à internet e equipamentos, mas também, à modalidade de ensino imposta, afetando a qualidade do ensino e da aprendizagem. Entretanto, também são apontados benefícios, como flexibilidade de horários e diminuição de gastos. Assim, conclui-se que o ERE ainda precisa ser repensado, sendo baseado nas necessidades sociais, culturais, econômicas e psicológicas dos discentes, e não somente, em questões operacionais e teóricas. Ressaltamos que a pesquisa está vinculado ao projeto de pesquisa cadastrado na Plataforma Brasil sob o número 33812620.5.0000.5528 e aprovado com o parecer 4.121.645 de 29 de junho de 2020.

Palavras-chave: Educação. Tecnologias educacionais. Pandemia.

Abstract: The pandemic of the new corona virus has changed the performance of several sectors around the world, including education, forcing people and institutions to remodel their activities, fulfilling social distance, as prevention to the spread of the virus. In the educational sector, emergency remote education was implemented as a possibility for continuing school activities. In this scenario, the research aims to understand, in the view of Brazilian students, what are the merits 
and demerits of Emergency Remote Education (ERE) for the educational context. The research is characterized as a qualitative case study, with the participation of 144 students through an online questionnaire, in which dissatisfaction was noted, related not only to access to the internet and equipment, but also to the imposed teaching modality, affecting the quality of teaching and learning. However, benefits are also pointed out, such as flexible hours and reduced expenses. Thus, it is concluded that the ERE still needs to be rethought, being based on the social, cultural, economic and psychological needs of the students, and not only, on operational and theoretical issues. We emphasize that the research is linked to the research project registered at Plataforma Brasil under number 33812620.5.0000.5528 and approved with the opinion 4,121,645 of June 29, 2020.

Keywords: Education. Educational technologies. Pandemic.

\section{Introdução}

O SARS-Cov-2, conhecido por novo Corona vírus, foi identificado pela primeira vez em Wuhan, na China, em dezembro de 2019, sendo transmitido de diferentes maneiras, inclusive pelo ar, e causando desde sintomas leves até a morte (BRASIL, 2020). O contágio acelerado e mortal do SARS-CoV-2 levou a Organização Mundial da Saúde (OMS) a decretar estado de pandemia (FIOCRUZ, 2020).

Apesar de uma queda considerável no mês de setembro, os números da COVID-19 ainda são altos, somando, até a penúltima semana deste mês ${ }^{1}$ cerca de 950 mil mortes, sendo mais de $50 \%$ delas localizadas no continente americano (OMS, 2020).

No âmbito educacional, as diversas instituições de ensino tiveram que se remodelar e sofrer mudanças operacionais imediatas, como por exemplo, a implantação da modalidade de Ensino Remoto. Contudo, esse novo formato de ensinar trouxe consigo diversos desafios para o Estado, gestores, professores, pais e discentes.

Apesar de ser considerada "um novo formato para o ensino", no Brasil, o uso das Tecnologias de Informação e Comunicação (TIC) no contexto educacional já é uma realidade, além da boa aceitação da educação a distância $(\mathrm{EaD})$, e de discussões há tempos, já iniciadas, sobre o ensino híbrido (EH). Porém, a extensão do isolamento social por meses, trouxe um terceiro nome: o Ensino Remoto Emergencial (ERE). É salutar, neste momento, entender que ERE, EaD e EH, são distintos e possuem em comum apenas o uso das tecnologias para a aprendizagem.

O EH é caracterizado pela dupla jornada de aprendizagem, parte realizada de forma on-line, e parte presencial, em um espaço físico, no qual o discente tenha autonomia para decidir seu modo e tempo de aprendizagem (HORN; STAKER, 2015). Já a modalidade EaD, possui divergências de conceituação. A EaD se caracteriza pela flexibilidade da educação, com relação ao modo e formato 
de aplicação, por exemplo: pode haver um contato virtual entre docente e discentes; ou pode não haver interação nenhuma entre discente-docente e discente-discente, no qual essa interação pode ser intermediada por um tutor à distância ou presencial (MORAN; VALENTE, 2015).

Arruda (2020), diferencia o ERE pela necessidade de interação que ele exige entre discentes e docentes, fazendo uso, quase sempre, de plataformas on-line, na qual ambos estão disponíveis simultaneamente, no qual também pode ser disponibilizado materiais, como vídeos e outros arquivos, aos discentes, se assim for necessário. Behar (2020) é ainda mais específica quanto a definição desse "novo ensino", referindo-se a "remoto", devido a distância geográfica entre docentes e discentes, enquanto o "emergencial", se devem às condições em que foi estabelecido, mudando todo o planejamento de aulas anual.

Atualmente, diversos trabalhos pesquisam e relatam a aceitação, a expansão, e o necessário uso das tecnologias na educação (BARROSO; ANTUNES, 2016; BRUZZI, 2016; DE ÁVILA, 2017; DE SOUZA, 2018); mas é necessário entender e refletir sobre os pontos fortes e fragilidades das modalidades de ensino que utilizam essas tecnologias.

Ainda que sejam identificadas dificuldades operacionais ou de acesso, por parte do público usuário e adeptos da modalidade de ensino $\mathrm{EaD}$, os benefícios e facilidades desse tipo de ensino se sobressaem, como por exemplo: o alcance e a expansão dessa modalidade, que chega até as regiões mais remotas; a diversidade de oferta de cursos; o formato de difusão do conhecimento; a flexibilidade de horários e maior acessibilidade ao ensino, dentre outros; além da conscientização por parte dos usuários das necessidade mínimas para esse tipo de ensino, como o acesso à internet e posse de equipamentos (computador, celular, tablet) mínimos para o acesso as aulas (APARECIDO; ZAMBON, 2020).

Realidade contrária é observada quanto ao uso de tecnologias no caso do ERE, no contexto da educação básica. Nesse caso, os problemas começam deste o acesso a essa modalidade de ensino, caracterizada principalmente pela falta de preparo (estrutural, operacional e econômico) dos discentes e pais para essa modalidade de ensino, que nem sempre podem arcar com as despesas de internet e aparelhos eletrônicos para o ensino digital. Outro problema é a adesão descontinua dessa modalidade no país. Ao analisar os dados da pesquisa do Centro de Inovação para a Educação Brasileira (CIEB), observa-se que algumas esferas estaduais e municipais aderiram a esse formato, dando continuidade ao ensino, outras não manifestaram interesse algum, fazendo com que discentes de diferentes níveis fiquem sem estudar por todo esse tempo (CIEB, 2020)

Diante do exposto, é necessário realizar uma reflexão acerca da implantação e desenvolvimento do Ensino Remoto Emergencial (ERE) no contexto educacional brasileiro, e para 
entender melhor esse processo, buscamos responder os seguintes questionamentos: O ERE está alcançando realmente todos os discentes? Quais as vantagens e desvantagens dessa modalidade de ensino? Como as instituições de ensino estão contribuindo para a implantação e desenvolvimento do ERE?

A partir desses questionamentos, essa pesquisa objetivou compreender, analisando a percepção discentes acerca das vantagens, desvantagens e desafios encontrados durante o ensino remoto no período de pandemia.

\section{Desenho metodológico}

Esta pesquisa caracteriza-se como um estudo de caso qualitativo. O estudo de caso permite que o pesquisador tenha uma visão ampla e real do seu objeto de pesquisa (YIN, 2015). Já a pesquisa qualitativa, busca não priorizar os fatores exatos, como a estrutura, mas sim, a relevância e a nova perspectiva que a resposta do pesquisado pode trazer para o contexto em pauta (DA SILVA, 2017).

Com relação aos participantes, a pesquisa contou com 144 respostas, de discentes em diferentes graus de ensino: 7 discentes de ensino médio (4,8\%), 1 de escola particular, 2 de escola integral-técnico, 3 de ensino público regular e 1 finalizou o Ensino Médio, porém ainda não ingressou no Superior; 7 discentes de pós-graduação (4,8\%), 4 de universidades estaduais, 2 de Institutos Federais, e 1 em escola de saúde pública; e outros 130 discentes de graduação (90,2\%), onde 4 são de faculdades/universidades privadas, 1 de Instituto Federal e 125 pertencentes a universidades estaduais. As idades variaram de 16 a 65 anos. Do total, 110 discentes identificaramse como do sexo feminino, 33 do sexo masculino, 1 não binário; apenas 1 preferiu não se identificar.

A coleta de dados ocorreu mediante a aplicação de um questionário on-line, utilizando a ferramenta Google Formulários, disponível em: https://forms.gle/Z7NGddd55GpSwnwH8. Este

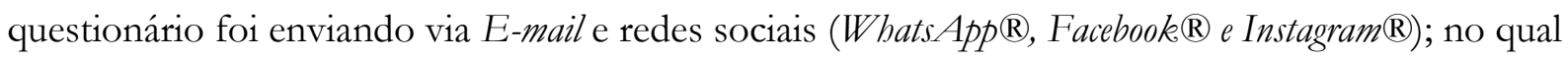
foi utilizado a técnica de bola de neve para amostragem, delimitada aos meses de junho e julho de 2020. O questionário contou com 20 perguntas objetivas e 1 subjetiva sendo as respostas divididas em duas categorias: a primeira buscou traçar o perfil social demográfico econômico dos participantes; e a segunda buscou entender a realidade de cada discente diante do Ensino Remoto Emergencial (ERE).

Os dados foram analisados descritivamente, no qual, primeiro, foi investigado sobre a acessibilidade dos discentes as TIC e a internet, que são os pontos chaves para a produção do ERE 
durante o isolamento social; e em seguida, procuramos saber sobre o uso de TIC antes e durante a pandemia, buscando pontos positivos e negativos em ambos os momentos e o que os discentes achavam da continuidade desse formato de ensino.

É importante ressaltar que a participação ocorreu de forma voluntária, e todos os participantes concordaram, por meio do Termo de Consentimento Pós Esclarecido, atendendo à competência do Conselho Nacional de Saúde, Resolução 510/2016 (BRASIL, 2016). Buscando preservar a identidade dos participantes, os discentes serão identificados por código, diferenciados de acordo com o nível de ensino: Básico (AM1, AM2... AM7), Superior (AS1, AS2... AS130) e PósGraduação (AP1, AP2... AP7). Ademais, este artigo é vinculado ao projeto de pesquisa cadastrado na Plataforma Brasil sob o número 33812620.5.0000.5528 e aprovado com o parecer 4.121.645 de 29 de junho de 2020.

Para analisar essas proposições elencadas anteriormente, os próximos tópicos serão dedicados a identificar as condições de equipamento e acesso à internet que os discentes dispunham, bem como, sequentemente, compreender sobre possíveis vantagens e desvantagens do Ensino Remoto Emergencial (ERE).

\section{$3 \mathrm{O}$ acesso aos equipamentos e à internet}

Nesse tópico, buscamos investigar e conhecer a fonte de renda dos participantes, uma vez que para se fazer o ensino por meios tecnológicos, como no caso do ERE, é necessário um aparato financeiro, que custeie acesso à internet e aparelhagem mínima qualificada. Partimos para essa reflexão, assim como Maciel, Lima e Gimenez (2016), que apontam que o fator econômico ganhou espaço no debate estudantil, e que os suportes tecnológico e físico não podem ser excluídos das políticas de permanência universitária. O mesmo pode ser dito do ensino básico, principalmente em tempos de ensino remoto.

Assim, perguntamos aos discentes se eles trabalhavam, mas apenas 39 participantes (27,1\%) disseram que sim; em contrapartida, 105 (72,9\%) afirmaram não trabalhar. Em relação à posse de bolsas estudantis, 60 participantes $(41,6 \%)$ não possuíam ou possuem nenhum tipo; ao passo que 84 discentes $(58,3 \%)$ possuem esse suporte.

A situação financeira dos discentes e a falta de auxílio estudantil ou bolsa de auxílio social, afeta diretamente o meio pelo qual estes têm acesso à internet, pois esse serviço no Brasil ainda não é gratuito e de qualidade e o acesso ao mesmo exige uma renda mínima destinada para isso. Silva et al. (2020), observa que não é difícil que famílias substituam o valor pago em mensalidades por 
um outro gasto ou busquem mantê-lo de uma forma mais branda no orçamento (SILVA et al., 2020).

Em nossa pesquisa, apenas 1 discente afirmou não ter nenhum acesso à internet, e a principal forma de acesso citada foi por banda larga, 126 (87,5\%), 14 participantes (9,7\%) acessam internet por meios alternativos; 3 (2\%) não responderam. Apesar de uma diferença clara de formas de acesso, a democratização do acesso à internet ainda necessita de atenção, e no ano de 2020 tornou-se primordial em todos os setores (BARROS; GOULART, 2016).

Adicionalmente a esse quesito, questionamos quais recursos tecnológicos os discentes dispunham para estudar, para identificar as condições para envio de atividades e utilização de plataformas on-line (Gráfico 1).

Como pode ser observado no gráfico abaixo, apesar da maioria dos discentes terem acesso e utilizarem o Notebook e o Smartphone como ferramenta de acesso à internet, um número considerável utiliza somente o Smartphone. Essa realidade é apontada pelo PNAD (BRASIL, 2018), que destaca, de 2016 a 2018, um crescimento de 3,1\% do uso dessa ferramenta em todo o Brasil.

Gráfico 1 - Quais recursos tecnológicos são utilizados para a realização do estudo

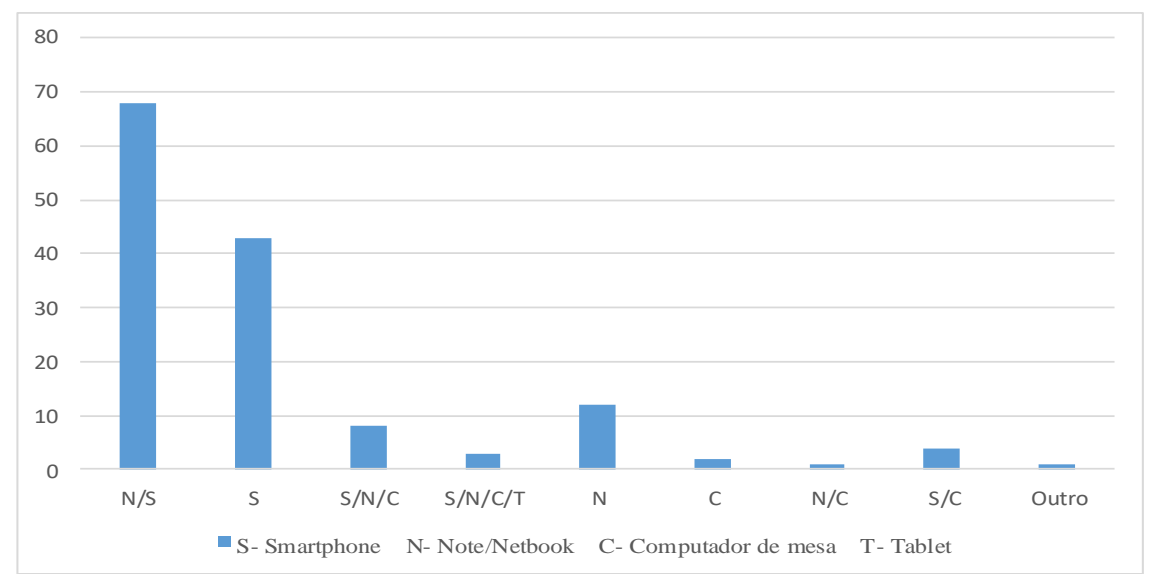

Fonte: Elaborado pelo autor.

O uso do Smartphone como principal ferramenta de acesso aos estudos deve ser considerada com atenção ao se pensar nos métodos e aplicativos que serão necessários para ter acesso as aulas e atividades, e no formato que estas atividades serão exigidas e executadas, pois sabemos que o Smartphone, apesar de ser um recurso mais acessível que o Notebook, possui limitações operacionais de uso com relação ao ensino.

Todavia, 42 (29,1\%) pesquisados não possuem cobertura de dados móveis e 26 discentes $(18 \%)$ não possuem acesso à internet em casa, e buscar esse acesso em outros lugares fica impossibilitado durante o período de isolamento social. O censo de Pesquisa Nacional por 
Amostra de Domićlios (PNAD) (BRASIL, 2018), aponta um crescimento no uso de internet nas casas brasileiras de 3,3\% a mais no ano de 2018 em relação a 2016. A pesquisa também destacou motivos do não acesso à internet de parte da população, o primeiro motivo, com 37, 4\%, dizia que a população não se interessavam por acessá-la, e o segundo motivo mais apontado foi o alto preço do serviço $(25,4 \%)$, o quarto motivo mais apontado (4,7\%) é a falta de aparelhos para o uso de internet. Esses dados nos levam de volta ao debate de que para que o ERE seja implementado é necessário levar-se em consideração as condições de custeio para isso.

Essa relação de situação financeira dos discentes com o ERE deve ser observada com atenção. Cunha, Silva e Silva (2020), salientam que a questão da desigualdade social presente no Brasil foi mais exposta nessa pandemia. Em seu trabalho, os autores afirmam que o uso das TIC na educação, tem um alto potencial, porém falta investimento e infraestrutura para sua implementação menos exclusiva. Para eles, ainda que grande parte dos discentes possuam um aparelho smartphone de boa qualidade, fatores externos, como o acesso à rede de celular e uma internet de boa qualidade, dificultam o acesso ao ensino remoto.

Somados todos os fatores citados aqui, ainda existe a problemática de utilização dessas ferramentas (Smartphone, notebook, tablet, entre outros), que na maioria das vezes, é feita de forma "dividida" entre as pessoas da família, comprometendo o tempo hábil destinado aos estudos; e no caso de compartilhamento da mesma rede domiciliar, a utilização de uma internet de qualidade, dificultando assim, a participação de atividades síncronas de forma efetiva.

\section{Ensino remoto em foco}

Com o objetivo de compreender o uso das TIC no contexto educacional, propusemos comparar o uso das tecnologias nas aulas dos discentes antes e durante a pandemia; para isso, perguntamos quais recursos tecnológicos já eram utilizadas em aulas e quais estão sendo usadas no ERE (Quadro 1). 
Quadro 1 - Recurso tecnológico utilizado antes e durante a pandemia

\begin{tabular}{|c|c|c|}
\hline Recurso Tecnológico & Antes da pandemia & Durante a pandemia \\
\hline Whats $A p p$ & 87 & 108 \\
\hline E-mail & 109 & 103 \\
\hline Mapas conceituais & 19 & 7 \\
\hline Slides & 61 & 34 \\
\hline Formulários Google & 10 & 22 \\
\hline Fóruns & 3 & 6 \\
\hline E-books & 18 & 14 \\
\hline YouTube & 17 & 3 \\
\hline Jogos digitais & 11 & 26 \\
\hline Gravação de vídeos & 9 & 1 \\
\hline HQ's & 6 & 9 \\
\hline Podcasts & 2 & 3 \\
\hline Cartilhas/Folders & 4 & 9 \\
\hline Editores de imagem e texto & 10 & - \\
\hline Desenhos & 3 & 75 \\
\hline Google Meet & 12 & 28 \\
\hline Lives & - & 3 \\
\hline
\end{tabular}

Fonte: Elaborado pelo autor.

No quadro acima é possível perceber que parte dos recursos analisados já eram usados antes da pandemia, mesmo que alguns ainda de forma bem tímida, como por exemplo, o Google Meet e gravação de vídeos. Isso pode está associado a não percepção da funcionalidade dessa ferramenta por parte de professores, discentes e gestores. Os recursos Whats App e E-mail foram aqueles que mais mantiveram a constância de uso entre os períodos analisados.

Observamos também, que outros recursos, tiveram sua frequência de uso aumentada mais que o dobro, como por exemplo: Formulários Google (8,3\%), fóruns (50\%), Youtube (18,7\%), gravação de vídeos (12,2\%), Podcast e Google Meet (44\%). Esse aumento está diretamente relacionado com a necessidade de comunicação e interação em tempos de pandemia, principalmente pelo uso do ERE. O ensino remoto trouxe consigo a necessidade e o despertar do uso de outras ferramentas, 


\section{Dialogia}

SILVA, Ana Carolina Oliveira; SOUSA, Shirlaine de Araújo; MENEZES, Jones Baroni Ferreira de. O ensino remoto na percepção discente: desafios e benefícios

que até então não eram utilizadas pelos discentes, mas que agora são exploradas, como o ensino através de lives e pelo Facebook.

Ao passo que vemos o aparecimento de novos recursos, observamos o decréscimo, já esperado, de alguns recursos mais utilizados na modalidade do ensino presencial, como o uso de slides, mapas conceituais, cartilhas/folders, HQ's e desenhos. Um resultado curioso foi a queda no uso de jogos digitais, mas isto pode está associado a falta de domínio desse recurso, que ainda é pouco difundido no ambiente escolar, e/ou a limitação por parte da ferramenta para utilização desse recurso fora do ambiente físico da escola/universidade, no qual, muitas vezes estes jogos estão pré-disponíveis nos aparelhos de laboratórios de informática ou em mídias físicas próprias.

Martins e Almeida (2020) analisam essa rápida expansão e, por que não, uma preferência pelas plataformas audiovisuais on-line, como uma consequência das cobranças de realizar o ensino imediato, para atender as demandas. As autoras chamam esse fenômeno de "táticas de sobrevivência", no qual todos os envolvidos no processo de ensino-aprendizagem foram obrigados a desenvolver essas habilidades de uso de tais recursos (MARTINS; ALMEIDA, 2020, p. 219).

Neste cenário, também é importante analisar a satisfação dos discentes para com o uso das tecnologias nesse período de isolamento e sua influência na aprendizagem.

A satisfação dos discente foi investigada segundo os critérios de uso dos recursos tecnológicos para a aprendizagem, o efetivo ensino-aprendizagem e o reflexo nas notas. Para isto, utilizamos a escala Likert, de 1 a 5, onde 1 indica que o entrevistado está muito insatisfeito e 5 que está muito satisfeito (Gráfico 2).

Gráfico 2 - Resultados da escala Likert sobre a satisfação discente com o uso de tecnologias na pandemia

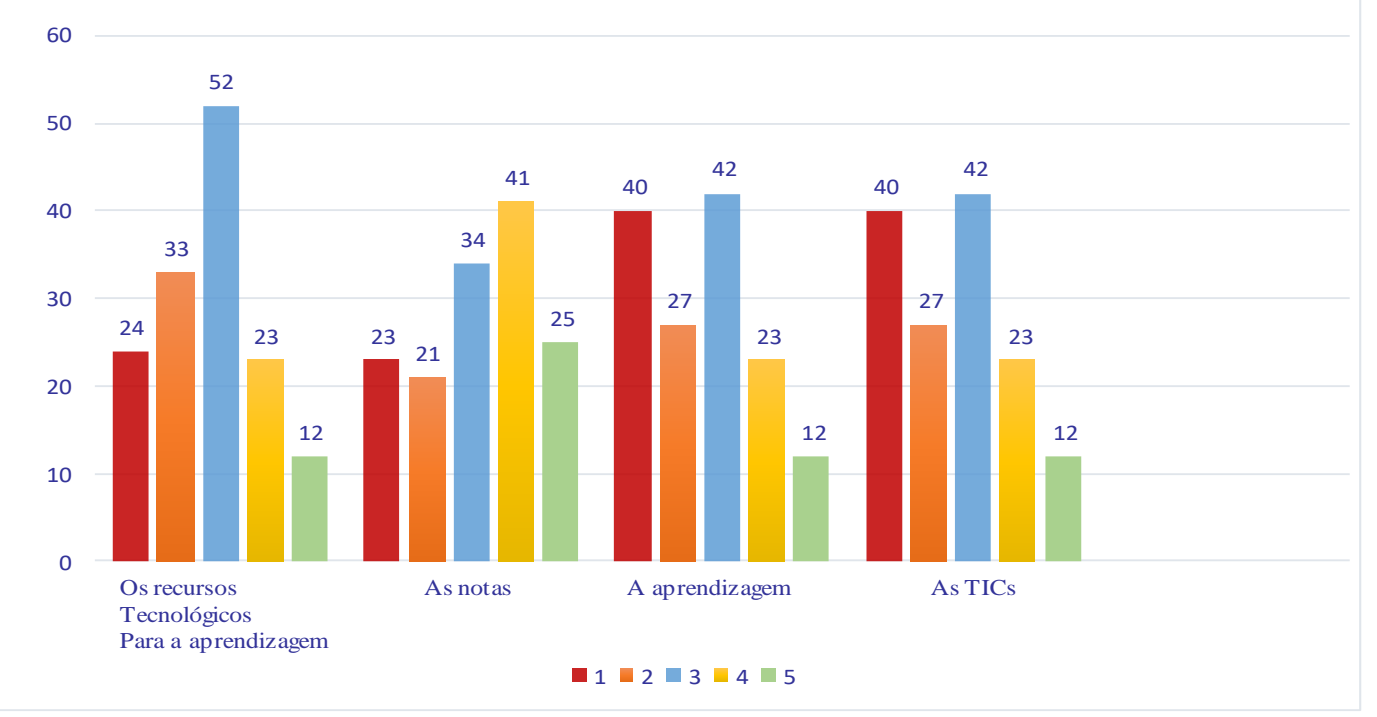

Fonte: Elaborado pelo autor 
Com relação à aceitação ao uso dos recursos tecnológicos para a aprendizagem o índice de satisfação foi considerado baixo, pois 52 discentes $(36,1 \%)$ dos entrevistados se demonstraram neutros ao tema e $57(39,5 \%)$ não aprovaram o mesmo. O índice de aprovação desse item é considerado baixo, apenas 35 discentes $(24,3 \%)$, e esse resultado pode representar uma difícil adaptação dos discentes com o uso desses recursos, o que é compreensível, afinal, as ferramentas síncronas e assíncronas são úteis, porém ainda não se equiparam as relações estabelecidas pela educação presencial (SILVA et al., 2018); além de nem sempre todas estarem presentes no cotidiano do processo de ensinagem dos discentes.

Apesar de não aprovarem o uso dos recursos tecnológicos, as notas durante o isolamento social foram bem avaliadas, onde 66 (45\%), discentes estão satisfeitos ou muito satisfeitos, ao passo que 34 discentes $(23,6 \%)$, posicionam-se como neutros. Esse resultado é um pouco contraditório se pensarmos que esse item está diretamente relacionado com o anterior; mas compreensível, se pensarmos que as formas de avaliação através do ERE ainda são pouco discutidas, frágeis e por esse motivo, podem não refletir, ou subestimar a funcionalidade do verdadeiro objeto avaliado.

Quanto à aprendizagem e a utilização das TIC, foi possível observar que 67 pesquisados (46,5\%) dos discentes estão insatisfeitos, 42 (29,1\%) mantem-se neutros e 35 (24,3\%) mostram-se satisfeitos. Essa taxa de insatisfação pode estar relacionada a pouca intimidade dos discentes com esses recursos, pela falta ou escasso uso; ou pelo fato desses discentes estarem mais adaptados à modalidade presencial, onde tinham interação com outros colegas e os professores, e repentinamente, foram obrigados a tornarem-se responsáveis pelo próprio aprendizado, destacando seus próprios horários, local, material e possuindo a "responsabilidade" pelo seu sucesso ou fracasso (BASSO et al., 2020; DE CUNHA; SILVA; SILVA, 2020).

Essa insatisfação também trás mais uma vez a importância e a necessidade de debater o uso, planejamento e aplicabilidade das TIC na educação, principalmente no formato do ERE. Esse uso deve ser feito de forma instruída, gradual e atendendo aos requisitos mínimos, como já foi discutido aqui neste trabalho. Menezes e Mota (2019) corroboram com esse pensamento, no qual afirmam que a aprendizagem por meio das TIC não se dá de forma impessoal e repentina; para os autores "é preciso refletir e entender como ocorre tal processo e como utilizar-se dele para otimizar o tempo de estudo e a aquisição de conhecimentos". (MENEZES; MOTA, 2019, p. 102).

No Gráfico 3 representamos as respostas aos questionamentos feitos com relação às dificuldades e os benefícios que os discentes encontram no Ensino Remoto Emergencial. Acerca das dificuldades destacamos, respectivamente, as três respostas mais citadas: "facilidade de 


\section{Dialogia}

SILVA, Ana Carolina Oliveira; SOUSA, Shirlaine de Araújo; MENEZES, Jones Baroni Ferreira de. O ensino remoto na percepção discente: desafios e benefícios

dispersão da atenção", "falta de espaço favorável" e "os recursos utilizados não favorecem a atividade".

Gráfico 3 - Dificuldades (a) e Benefícios (b) do Ensino Remoto Emergencial

(a)

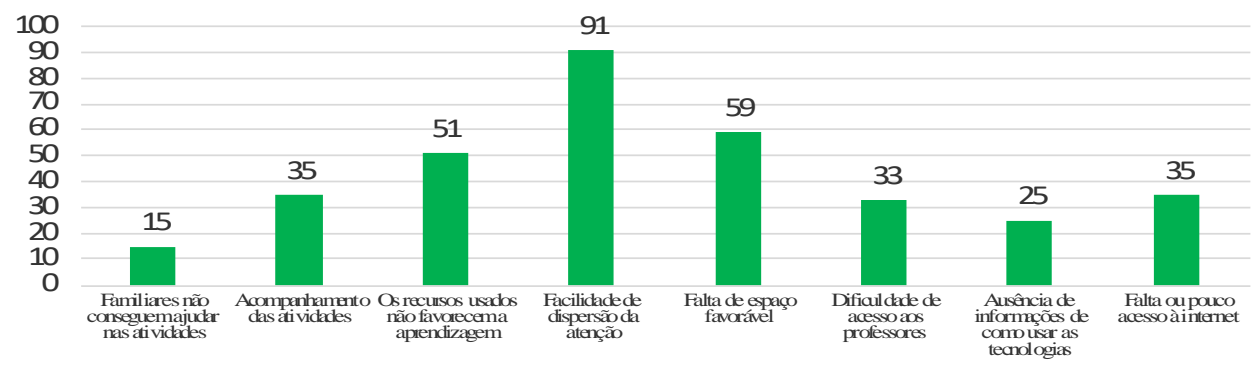

(b)

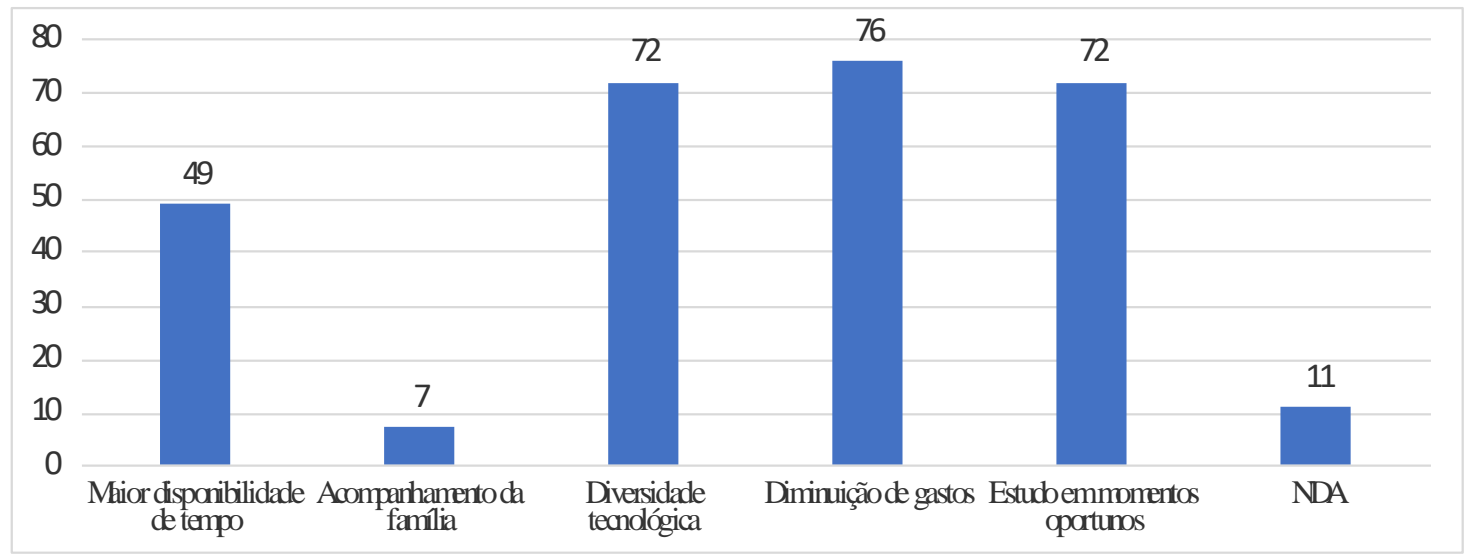

Fonte: Elaborado pelo autor.

A dispersão de atenção, que representa $63 \%$ dos apontamentos, chama à atenção pelo fato de não se referir a tecnologia em si, ou seja, a maior dificuldade dos discentes está em concentrar-se. Martins e Almeida (2020, p. 222) discorrem sobre a emancipação da ideia de que a educação digital não se faz apenas com internet e aparelhos:

A educação on-line não é compreendida exclusivamente pelas tecnologias digitais. Também é amparada pela interatividade, afetividade, colaboração, coautoria, aprendizagem significativa, avaliação adequada, mediação docente implicada, relação síncrono assíncrono, entre outros, buscando a visão de que aprendemos qualitativamente nas trocas e nas construções conjuntas. 
A “falta de espaço favorável” está diretamente relacionada com a questão da dispersão da atenção e uma influencia diretamente a outra. Essa dificuldade mais uma vez expõem as desigualdades sociais e estruturais que prejudicam a promoção de uma igualdade maior no processo educacional, visto que a maioria dos discentes não dispõe de um espaço saudável para estudar em seus domicílios. A terceira dificuldade, que versa sobre "os recursos utilizados não favorecem a atividade", reflete a falta de planejamento e preparo das atividades para atingir os objetivos da aprendizagem, esse fator reforça, e é mais uma vez possivelmente explicado pela instituição do ensino remoto de forma "repentina", imediata e sem preparo dos seus pares e participantes do processo.

Com relação aos benefícios, destacamos também as três respostas mais citadas: “diminuição de gastos", "diversidade tecnológica" e "estudos em momentos oportunos". A diminuição de gastos pode está associada, aos gastos de deslocamento e manutenção (alimentação, cópias, vestimenta, entre outros) do estudante no ambiente universitário; a diversidade tecnológica foi citada como um multiplicidade de métodos, recursos e possibilidades que as tecnologias oferecem para serem exploradas, de forma correta e adequada com cada objetivo e modalidade de ensino; e os estudos em momentos oportunos, reflete a flexibilidade de horários que o ERE proporciona, que está totalmente relacionada com a quarta resposta mais citada, disponibilidade de tempo.

Quando questionados sobre quais medidas poderiam ser tomadas na educação nos tempos atuais (Gráfico 4), no qual os entrevistados puderam citar mais de uma opção, 65 (45,8\%) dos discentes se mostraram favoráveis ao ensino remoto, desde que este seja planejado e executado dentro das condições mínimas viáveis.

Hoffman et al. (2020), também afirma a importância do ERE nos dias de isolamento social, servindo para manter os discentes e professores vinculados, de certo modo, também fazendo-se presente no ensino, para que os discentes não se distanciem da escola/universidade. 


\section{Dialogia}

SILVA, Ana Carolina Oliveira; SOUSA, Shirlaine de Araújo; MENEZES, Jones Baroni Ferreira de. O ensino remoto na percepção discente: desafios e benefícios

Gráfico 4 - Quais medidas poderiam ser tomadas na educação atual

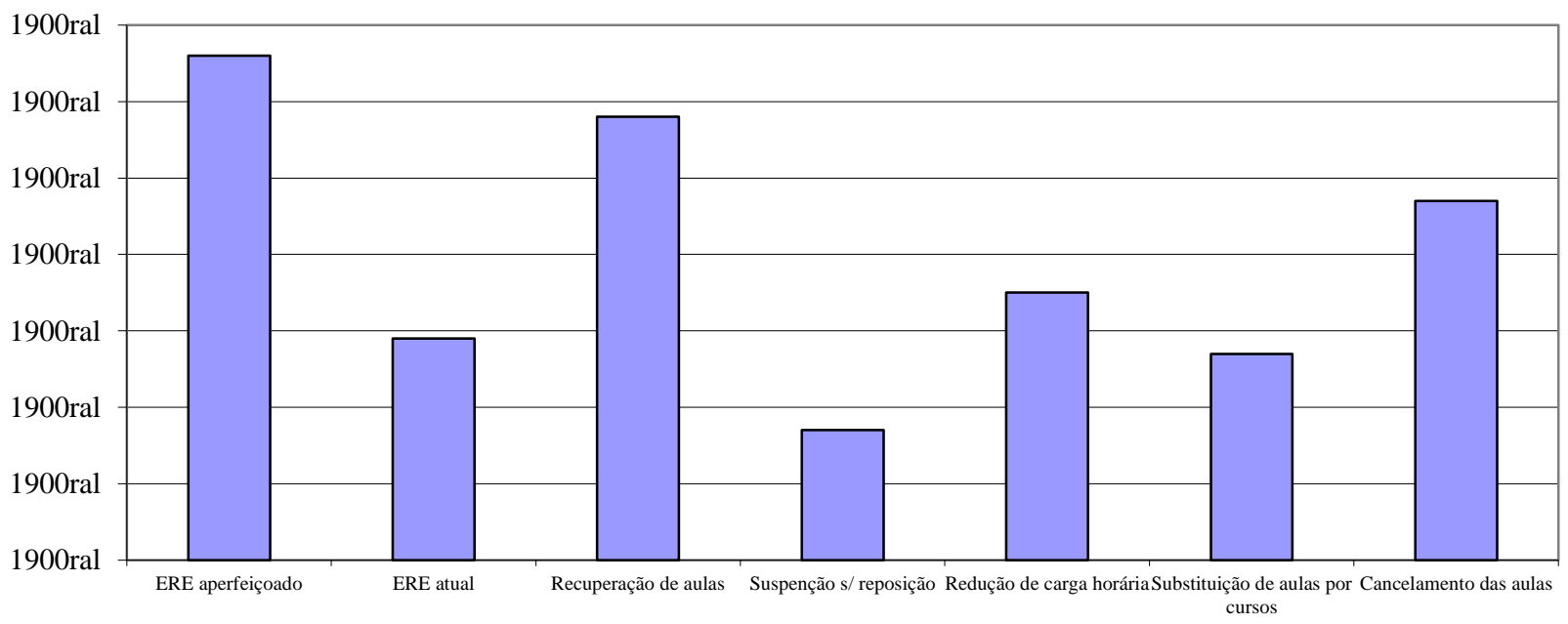

Fonte: Elaborado pelo autor.

É importante observar que a pesquisa revela uma rejeição considerável ao formato do ERE atual empregado nas escolas e universidade, sendo apontado por apenas 29 discentes (20,1\%), e o interesse dos discentes pelas aulas presenciais, indicado no interesse pela recuperação das aulas na modalidade presencial ou cancelamento das mesmas no formato remoto. Isso pode evidenciar a importância do ensino presencial e a importância do trabalho do professor no processo de ensino aprendizagem. Essa afirmação pode ser confirmada no relato de um discente, que dentre os 144 participantes da pesquisa, não escolheu nenhuma das opções presentes no gráfico 4, afirmando que:

\footnotetext{
AS 24: Qualquer uma das alternativas trás prejuízo na questão do aprendizado, acho que não existe uma melhor estratégia para se trabalhar durante a Pandemia, apesar dos meios digitais, muitos estudantes não tem acesso a internet e os conteúdos repassados não são totalmente absorvidos.
}

Perguntamos aos discentes se eles consideram ideal o aproveitamento das disciplinas através do Ensino Remoto, para finalizar o semestre letivo; 100 participantes (69,4\%) relataram que esse aproveitamento não é positivo, contra 44 participantes (30,5\%) que não o veem como negativo.

Por fim, indagamos aos participantes qual seu posicionamento caso o isolamento não permitisse o retorno presencial das aulas no segundo semestre de 2020. Do total, 65 participantes $(45,1 \%)$ relataram que seria melhor utilizar o Ensino Remoto até o início presencial das atividades; em contrapartida, 79 discentes $(54,9 \%)$ optaram por não haver retorno às aulas até que a modalidade presencial pudesse ser oferecida novamente. 
As respostas dos discentes expõe uma clara incerteza com relação à educação no período pandêmico. Uma evidência disso, é que a maioria dos discentes não conseguem adquirir conhecimentos funcionais significativos, talvez devido a radicalidade como lhes foi imposto o ensino, ou talvez por problemas mentais e emocionais acarretados a partir da situação mundial. Sobre isso, Amaral e Polydoro (2020), identificaram inúmeros sentimentos externados por discentes durante esse período, como: medo de não concluir o curso ou o semestre, receio sobre quando poderia ser feito o retorno presencial e a falta de concentração; alguns destes também citados em nossa pesquisa.

Diante do exposto nesta pesquisa é fato que o setor educacional, assim como outros setores, não estava preparado para o enfretamento de um momento pandêmico. A situação emergencial de possibilidade de implementação do ensino remoto para dar continuidade ao ano letivo, trouxe consigo as dificuldades e principais dilemas enfrentados pelas desigualdades sociais e pelo setor educacional. Pesquisas mais amplas e específicas são necessárias para que possamos discutir de forma mais fiel e efetiva as possibilidades de enfretamento dessas dificuldades, e esta pesquisa reflete o passo inicial da necessidade dessa reflexão mais ampla e apurada.

\section{Considerações finais}

A pandemia do novo Corona vírus deixou claro um Brasil dividido socialmente, culturalmente e economicamente, com vários dilemas e lacunas para serem sanadas no setor educacional, principalmente na educação pública. Nossa pesquisa demonstrou que muitos discentes estão buscando continuar seus estudos por meios digitais, mas uma série de fatores dificultam essa continuidade efetiva, dentre eles: uma internet de péssima qualidade, isso quando a mesma é existente; meios de acesso limitados; falta de equipamentos mínimos; pouca familiaridade com tecnologias de ensino, ocasionando a baixa eficiência de aprendizagem, tanto pelo discente, quanto pelo docente; falta de um espaço adequado e saudável para o cumprimento das obrigações escolares ou acadêmicas, entre outros fatores associados aos anteriores.

Ficou evidente também que apesar da importância e vantagens indiscutíveis do ensino presencial, o problema não é a utilização do ensino remoto, e sim, a forma como este foi do implementado, sem planejamento, capacitação e estruturação das mínimas condições viáveis de suporte entre as principais partes envolvidas nessa modalidade de ensino, para os discentes e professores.

Por fim, esse estudo é uma amostra do que deve ser pensado ao se propor o ERE como modalidade de ensino; pois é importante levar em consideração a opinião dos discentes nos 
planejamentos de implementação dessa modalidade, uma vez que, são estes os sujeitos que usufruem dos modelos educacionais, beneficiados quando este é positivo e altamente prejudicados, quando esses modelos são aplicados erroneamente.

${ }^{1}$ A data de recolhimentos dos dados correspondeu a penúltima semana do mês de setembro (24 set 2020)

\section{Referências}

AMARAL, Eliana; POLYDORO, Soely. OS DESAFIOS DA MUDANÇA PARA O ENSINO REMOTO EMERGENCIAL NA GRADUAÇÃO NA UNICAMP-BRASIL. Linha Mestra, n. 41a, p. 52-62, 2020.

APARECIDO, Cristina Tischer Ranalli; ZAMBON, Marcelo Socorro. DEMOCRATIZAÇÃO DA EDUCAÇÃO E A EXPANSÃO DO ENSINO A DISTÂNCIA NO BRASIL. Teoria \& Prática: Revista de Humanidades, Ciências Sociais e Cultura, v. 2, n. 1, p. 1-13, 2020.

ARRUDA, Eucidio Pimenta. EDUCAÇÃO REMOTA EMERGENCIAL: elementos para políticas públicas na educação brasileira em tempos de Covid-19. EmRede-Revista de Educação a Distância, v. 7, n. 1, p. 257-275, 2020.

BARROS, Bruno Mello Correa de; GOULART, Gil Monteiro. O ACESSO À INTERNET NO BRASIL E À INCLUSÃO DIGITAL: UMA ANÁLISE DOS AVANÇOS E RETROCESSOS DO PROGRAMA NACIONAL DE BANDA LARGA-PNBL. Seminário Nacional Demandas Sociais e Políticas Públicas na Sociedade Contemporânea, 2016.

BARROSO, Felipe; ANTUNES, Mariana. TECNOLOGIA NA EDUCAÇÃO: FERRAMENTAS DIGITAIS FACILITADORAS DA PRÁTICA DOCENTE. Revista Pesquisa e Debate em Educação, v. 5, n. 1, 2016.

BASSO, Silvia Eliane de Oliveira; SANTOS, Renata Oliveira; OLIVEIRA, Dayane Horwat Imbriani de; MERTZIG, Patrícia Lakchmi Leite; COSTA, Maria Luisa Furlan. EaD, CURRÍCULO E HEGEMONIA: O NECESSÁRIO DEBATE. Revista EmRede. v. 7, n. 1, p. 225-241, 2020.

BEHAR, Patricia Alejandra. O ENSINO REMOTO EMERGENCIAL E A EDUCAÇÃO A DISTÂNCIA. Rio Grande do Sul: UFRGS, 2020. Disponível em: https://www.ufrgs.br/coronavirus/base/artigo-o-ensino-remoto-emergencial-e-a-educacao-a-distancia/.

BRASIL. MEC. Decreto No 343, de 17 de Março de 2020.

BRASIL. MEC. Decreto No 544, de 16 de Junho de 2020.

BRASIL. MEC. Resolução Nº 510, de 7 de abril de 2016. 


\section{Dialogia}

SILVA, Ana Carolina Oliveira; SOUSA, Shirlaine de Araújo; MENEZES, Jones Baroni Ferreira de. O ensino remoto na percepção discente: desafios e benefícios

BRASIL. Ministério da Saúde. O QUE É COVID-19?. 2020. Disponível em: < https://coronavirus.saude.gov.br/sobre-a-doenca\#O-que-e-covid> Acesso em 02 set 2020.

BRASIL. Pesquisa Nacional por Amostra de Domicílios (PNAD), 2018. Disponível em: ftp://ftp.ibge.gov.br/Trabalho e Rendimento/Pesquisa Nacional por Amostra de Domicilio s continua/Anual/Acesso Internet Televisao e Posse Telefone Movel 2018/Analise dos re sultados TIC 2018.pdf

BRUZZI, Demerval Guilarducci. USO DA TECNOLOGIA NA EDUCACÃO, DA HISTÓRIA À REALIDADE ATUAL. Revista Polyphonía, v. 27, n. 1, p. 475-483, 2016.

CIEB. PLANEJAMENTO DAS SECRETARIAS DE EDUCAÇÃO PARA O ENSINO REMOTO. 2020. Disponível em: < https://cieb.net.br/wp-content/uploads/2020/04/CIEBPlanejamento-Secretarias-de-Educac\%C3\%A3o-para-Ensino-Remoto-030420.pdf > Acesso em 03 set 2020.

DA CUNHA, Leonardo Ferreira Farias; DE SOUZA SILVA, Alcineia; DA SILVA, Aurênio Pereira. O ENSINO REMOTO NO BRASIL EM TEMPOS DE PANDEMIA: DIÁLOGOS ACERCA DA QUALIDADE E DO DIREITO E ACESSO À EDUCAÇÃO. REVISTA COM CENSO: ESTUDOS EDUCACIONAIS DO DISTRITO FEDERAL, v. 7, n. 3, p. 27-37, 2020.

DA FIOCRUZ BRASÍLIA, Assessoria de Comunicação. O QUE É PANDEMIA E O QUE MUDA COM A DECLARAÇÃO DA OMS?. 2020.

DA SILVA, Anielson Barbosa; GODOY, Arilda Schmidt; ANDION, Carolina; GODOI, Christiana Kleinubing; CUNHA, Cristiano José Castro de Almeida; BALSINI, Cristina Pereira Vecchio; ICHIKAWA, Elisa Yoshie; FREITAS, Henrique; BLIKSTEIN, Izidoro; MACKE, Janaina; NETO, João Roman; SANTOS, Lucy Woellner dos; ALQUINO, Mário Alves; SERVA, Maurício; OLIVEIRA, Mírian; VIEIRA, Paulo Freire; MATTOS, Pedro Lincoln C. L. de; BANDEIRA DE MELO, Rodrigo; BOEIRA, Sérgio Luís. PESQUISA QUALITATIVA EM ESTUDOS ORGANIZACIONAIS. 2. ed. Saraiva Educação SA, 2017.

DE ÁVILA, Éverton Gonçalves. INVESTIGANDO A ERA INFORMACIONAL: SUBJETIVIDADE, TICS E EDUCAÇÃO. IN: INVESTIGACIÓN EN INFORMACIÓN, DOCUMENTACIÓN Y SOCIEDAD: PERSPECTIVAS Y TENDENCIAS. Departamento de Biblioteconomía y Documentación, 2017. p. 213-226.

DE SOUZA, Liana Estela Merladete. DO (RE) CONHECIMENTO DE COMPETÊNCIAS, UM NOVO PAPEL PARA AS TICS NA EDUCAÇÃO SUPERIOR. DoisAC, 2018.

HOFFMANN, Wesley Pinto; LOSS, Raquel Aparecida; GUEDES, Giorgo Ferreira; MEXIA, Alexandre Agostinho; GUEDES, Sumaya Ferreira; A IMPORTÂNCIA DO ENSINO REMOTO: UM RELATO DA UNIVERSIDADE DO ESTADO DE MATO GROSSO. Research, Society and Development, v. 9, n. 9, p. e813998084-e813998084, 2020.

HORN, Michael B.; STAKER, Heather; CHRISTENSEN, Clayton. BLENDED: USANDO A INOVAÇÃO DISRUPTIVA PARA APRIMORAR A EDUCAÇÃO. Penso Editora, 2015. 


\section{Dialogia}

SILVA, Ana Carolina Oliveira; SOUSA, Shirlaine de Araújo; MENEZES, Jones Baroni Ferreira de. O ensino remoto na percepção discente: desafios e benefícios

MACIEL, Carina Elisabeth; LIMA, Elizeth Gonzaga dos Santos; GIMENEZ, Felipe Vieira. POLÍTICAS E PERMANÊNCIA PARA ESTUDANTES NA EDUCAÇÃO SUPERIOR. Revista Brasileira de Política e Administração da Educação-Periódico científico editado pela ANPAE, v. 32, n. 3, p. 759-781, 2016.

MARTINS, Vivian; ALMEIDA, Joelma. EDUCAÇÃO EM TEMPOS DE PANDEMIA NO BRASIL: SABERES FAZERES ESCOLARES EM EXPOSIÇÃO NAS REDES. Revista Docência e Cibercultura, v. 4, n. 2, p. 215-224, 2020.

MENEZES, Jones Baroni Ferreira; MOTA, Francisca Daniela Lira. O USO DAS TECNOLOGIAS EDUCACIONAIS DURANTE O EXERCÍCIO DA MONITORIA ACADÊMICA EM UM CURSO DE CIÊNCIAS BIOLÓGICAS. Revista Brasileira de Iniciação Científica, v. 6, n. 1, p. 96-108, 2018.

OMS - ORGANIZAÇÃO MUNDIAL DA SAÚDE. CORONAVIRUS DISEASE (COVID19) SITUATION REPORT. 2020. Disponível em:<https://www.who.int/docs/defaultsource/coronaviruse/situation-reports /20200921-weekly-epi-update-6.pdf?sfvrsn=d9cf9496_6> Acesso em 24 set. 2020.

MORAN, José Manuel; VALENTE, José Armando. EDUCAÇÃO A DISTANCIA. Summus Editorial, 2015.

PETRY, Jonas Fernando; VERGINI, Danielle Paná; BORGES, Gustavo da Rosa; KLANN, Roberto Carlos. UMA ANÁLISE DA REPRESENTATIVIDADE DO ENSINO A DISTÂNCIA NO BRASIL. Diálogos Interdisciplinares, v. 5, n. 1, p. 123-138, 2016.

SILVA, José Geovane Pinheiro e; DOS ANJOS, Helton John Rodrigues; MARINHO, Márcia Machado; MARINHO, Gabrielle Silva; MENDES, Francisco Rogênio Da Silva; MARINHO, Emmanuel Silva. AVALIAÇÃO DAS FERRAMENTAS DE DESENVOLVIMENTO DA PRESENCIALIDADE VIRTUAL, APRENDIZAGEM AUTÔNOMA E COLABORATIVA PRESENTES NO AVA MOODLEC. Redin-Revista Educacional Interdisciplinar, v. 7, n. 1, 2018.

SILVA, Thiago Christiano; COELHO, Florângela Cunha; EHRL, Philipp; TABAK, Benjamin Miranda. ACESSO À INTERNET EM PERÍODOS RECESSIVOS: O CASO DO BRASIL 1. Revista Ibérica de Sistemas e Tecnologias de Informação, n. E28, p. 486-497, 2020.

YIN, Robert K. ESTUDO DE CASO-: PLANEJAMENTO E MÉTODOS. 5. ed. Bookman editora, 2015.

Recebido em: 26 jul. 2020 / Aprovado em: 01 dez. 2020

Cite como

(ABNT NBR 6023:2018) 


\section{Dialogia}

SILVA, Ana Carolina Oliveira; SOUSA, Shirlaine de Araújo; MENEZES, Jones Baroni Ferreira de. O ensino remoto na percepção discente: desafios e benefícios

SILVA, Ana Carolina Oliveira; SOUSA, Shirlaine de Araújo; MENEZES, Jones Baroni Ferreira de. O ensino remoto na percepção discente: desafios e benefícios. Dialogia, São Paulo, n. 36, p. 298-315, set./ set. 2020. Disponível em: https://doi.org/10.5585/dialogia.n36.18383.

\section{American Psychological Association (APA)}

Silva, A. C. O., Sousa, S. de A., \& Menezes, J. B. F. de (2020, set./dez.). O ensino remoto na percepção discente: desafios e benefícios. Dialogia, São Paulo, 36, p. 298-315.

https://doi.org/10.5585/dialogia.n36.18383. 